\title{
Em DefeSa da Química
}

Recebeu recentemente a Sociedade Portuguesa de Química (SPQ), na pessoa do Doutor Joaquim Faria (Presidente da Delegação do Porto da SPQ), uma mensagem de colegas nossos do grupo disciplinar de Física e Química de uma escola secundária. Transcreve-se em seguida a referida mensagem com as necessárias adaptações apenas para manter o anonimato da escola:

\section{Exmos Senhores,}

Enquanto professores de Física e de Química consideramos fundamental que os alunos frequentem as disciplinas de Física e de Química do $12^{\circ}$ ano, tendo em conta os cursos científicos superiores que pretendam frequentar, de forma a assegurarem a melhor preparação possível para os referidos cursos. Compreendemos a necessidade da frequência destas disciplinas por todos os alunos do curso Ciências e Tecnologias uma vez que lhes permite desenvolver competências para melhor exercerem a cidadania. No entanto, constatamos que nem toda a comunidade educativa se apercebe da importância do estudo destas disciplinas experimentais na formação integral dos alunos.

Neste contexto, e em consequência do deliberado em Conselho Pedagógico da nossa escola (pedido ao grupo disciplinar de fundamentação para a inclusão destas disciplinas na oferta curricular da escola), vimos solicitar o Vosso apoio, com algum carácter de urgência, no envio de um parecer para apresentarmos ao referido Órgão Pedagógico, com a finalidade de o sensibilizar e informar da relevância de incluir estas disciplinas na oferta educativa da escola.

Pensamos que um parecer, emitido por entidades de reconhecida competência como a SPQ SPF e Equipas Responsáveis pela Elaboração dos Programas de Física e de Química do Ensino Secundário, que ateste a importância destas disciplinas, é muito importante para sensibilizar a comunidade escolar. Consideramos ainda que seria muito útil que o Vosso documento descriminasse os cursos superiores para os quais os conteúdos programáticos dessas disciplinas são pré-requisitos fundamentais para uma formação académica com sucesso. ${ }^{1}$

É bem possivel que outras escolas, em outras ocasiões, tenham tido problema idêntico. É também plausível que estas questões tenham já sido postas por vários colegas nossos. É assim da maior relevância que se dê uma resposta pública a estas questões.

A importância de continuar a dispor do ensino da Química nos cursos do secundário prende-se com três ordens de razões: 1) a importância da Química nos dias de hoje; 2) a importância da Química numa cultura sólida e, 3) a noção de que nem tudo se obtém sem trabalho.

1) A Química assume hoje um papel fulcral numa Sociedade Tecnológica como a nossa. Praticamente nada do que fazemos na nossa vida diária está desligado da Química. Vestimos roupas de poliéster, meias de nylon e impermeáveis de oleado. Usamos talheres de aço inoxidável e guardamos a comida no frigorífico em caixas de plástico. Em todos estes materiais a química desempenha um papel fundamental na sua obtenção. Um dos exemplos mais marcantes na nossa sociedade é o automóvel. É feito com peças metálicas fabricadas numa siderurgia onde se dão reacções entre o ferro e outros metais/ou compostos para obtermos as ligas metálicas que hoje se usam. Grande parte das peças de um automóvel é "plástico",

\footnotetext{
1 Segundo a legislação actualmente em vigor (http://www.mctes.pt/ archive/doc/dl_2008_090.pdf) qualquer curso do ensino secundário permite concorrer ao ingresso em qualquer curso do ensino superior. desde que os alunos tenham as disciplinas definidas como provas de ingresso para os cursos de ensino superior que pretendam vir a frequentar (http://tirateimas.terradepaixao.net/?page_id=84). Existem assim muitos cursos do ensino superior que têm a disciplina de Quimica e Fisica (Q ou F) como prova de ingresso, mas o mais frequente é estar como alternativa a outras disciplinas (p. ex. Matemática, Biologia e Geologia, Geometria Descritiva, Economia ou Geografia). Na opinião do autor, se todos os alunos de todos os cursos do ensino secundário têm Filosofia, Português ou Educação Física, porque não ter também Matemática, Física e Química. Tal parece ser também o entendimento actual do Ministério da Ciência Tecnologia e também o entendimento actual do Ministério da Ciência Tecnologia e
Ensino Superior. Na aplicação do artigo $181^{\circ}$ da Lei n ${ }^{\circ} 62 / 2007$ de 10 Setembro (regime jurídico das instituições de Ensino Superior) está em preparação uma portaria em que se propõe no $n^{\circ} 2$ do seu artigo 10 a disciplina de "Física e Química " gatória em todos os cursos de Ciências Físicas (área 44), Ciências da Vida (área 42) e Engenharias, já em 2010
}

isto é, polímeros que foram obtidos por diversas reacções químicas. $O$ motor do carro, seja a gasolina ou a gasóleo, é um excelente exemplo de uma reacção de combustão. Os pneus foram obtidos a partir de borracha natural ou do petróleo através de uma reacção de vulcanização ou similar. Nada disto seria possível sem a Química.

2) Excluir a Química (ou outra Ciência qualquer) das possibilidades de escolha dos alunos é um atentado à cultura dos mais novos. Existe em alguns meios a ideia que a Química (ou a Física ou a Matemática) não faz falta a quem não tencione seguir essa área do conhecimento. É o mesmo que dizer que o conhecimento da Língua Portuguesa só interessa a quem se dedique às línguas ou à filologia. Tão ignorante é aquele que não sabe quem é Picasso, Mozart ou Camões como o que não sabe quem é Newton ou Lavoisier. "O binómio de Newton é tão belo como a Vénus de Milo. O que há é pouca gente para dar por isso." já dizia Fernando Pessoa (usando o seu heterónimo Álvaro de Campos). É fundamental que cada vez haja mais pessoas a dar por isso. A Cultura de uma pessoa e de todo um povo é uma rede de conhecimentos que se interpenetram e que juntos adquirem mais força. Eliminar alguma, ou algumas, das malhas dessa rede só a enfraquece. Impedir aos nossos alunos que possam aprender Química é cercear o futuro dos nossos jovens.

3) $O$ terceiro argumento prende-se com a suposta dificuldade da aprendizagem da Química. Na realidade a Química não é difícil, mas requer algum trabalho e algum esforço. Se se pretender retirar tudo o que dá trabalho, e infelizmente tal tem-se verificado nos últimos anos, teríamos que estender o conceito a todas as áreas do saber. Na Língua Portuguesa não se ensinaria Fernando Pessoa e os seus heterónimos porque dão trabalho, apesar de ser um vulto incontornável da nossa Cultura. Na Filosofia teria 
que se banir Sartre, pois a sua leitura é trabalhosa. Na Língua Inglesa excluiríamos Shakespeare pois a sua linguagem está ultrapassada e dá trabalho entendê-lo. Levando um pouco ao limite, podíamos sugerir que fosse retirada a cadeira de Anatomia dos cursos de Medicina; dá muito trabalho. Não sei, depois, que médicos teríamos para nos tratar. O simples facto de algo ser trabalhoso não é argumento que se possa invocar a não ser por má fé ou ignorância.

Num país e num tempo em que ideias erradas são criadas e alimentadas por tantos, é fundamental que aqueles que abraçaram a missão de transmitir os conhecimentos, os professores, não cedam à tentação de seguir a corrente. Sejam professores do $1^{\circ} \mathrm{ciclo}$, $3^{\circ}$ ciclo ou de cursos superiores é necessário e urgente que se dê um sinal de que é possível que as coisas sejam diferentes. É preciso que os alunos continuem a ter as várias opções em aberto, é preciso e necessário que possam entender o mundo que os rodeia, é preciso e necessário que tenham uma cultura completa e equilibrada, é preciso e necessário que saibam que há temas e matérias trabalhosos e que até por isso são muitas vezes mais compensadores.
E é preciso que haja professores que continuem a lutar para que isto aconteça. É preciso e necessário que se mude as mentalidades e que não se deixe o nosso ensino seguir em direcção ao facilitismo, ao estreitamento de horizontes e à ignorância encapotada. Obrigado aos que entenderem esta mensagem, pois, esses sim, estão a construir um melhor futuro para os nossos jovens e para todos nós.

João Paulo Leal Secretário Geral Adjunto Direcção da SPQ

\section{Final das Olimpíadas de Química.mais 2009}

A Final realizada no Departamento de Química da Universidade de Aveiro no dia 9 de Maio, foram encontrados os vencedores absolutos das Olimpíadas Portuguesas de Química:

Medalha de Ouro

Bruno Tiago Lopes Carneiro Devesa - Colégio Internato dos Carvalhos

Medalha de Prata

Gonçalo Vitorino Bonifácio - ES José Saramago(Mafra)

Medalha de Bronze

David Armando de Oliveira Pinto - Colégio Internato dos Carvalhos

Juntamente com estes 3 medalhados, foramtambémapurados paraa fase preparatória das competições internacionais de 2010 os seguintes participantes:

- Marta Cristina Neves Aguiar - ES de Homem Cristo (Aveiro) - Alexandre Faia Carvalho - ES/B3 de Peniche Maria de Azevedo António Machado da Silva - ES/B3 de Peniche - Gonçalo Filipe Moura Ferreira - ES de Francisco Rodrigues Lobo (Leiria) - Ana Catarina Rodrigues dos Santos e Silva - Colégio Internato dos Carvalhos - Sergio Bruno Moura Marcos - ES/B3 Rio Tinto Jorge Pedro Martins Nogueiro - ES/B3 Emídio Garcia (Bragança)

O Prémio "Melhor Escola", que distingue a instituição com o melhor conjunto de resultados dos seus 3 participantes foi atribuído ao Colégio Internato dos Carvalhos, que teve dois dos seus alunos medalhados. Os 27 alunos participantes na Final nacio- nal foram apurados nas 3 semifinais realizadas a 14 de Março em Aveiro, Lisboa e Porto.

\section{** Lista dos Participantes na Final ** \\ Vencedores da Semifinal de Aveiro (Departamento de Química, Univer- sidade de Aveiro)}

Medalhas de Ouro

ES de Homem Cristo

Marta Cristina Neves Aguiar

Daniel Martins

Pedro Jorge Vieira

Professor: Maria Fernanda Quinta e Dulcina Carvalho

Medalhas de Prata

ES/B3 de Peniche

Alexandre Faia Carvalho

Maria de Azevedo António Machado da Silva

Geisa Silva Félix

Professor: Maria Leonor Chagas Marques e Manuel Lopes Martins

\section{Medalhas de Bronze}

ES de Francisco Rodrigues Lobo

André Guarda

Gonçalo Filipe Moura Ferreira

João Carlos Marques

Professor: Maria Amélia Moura

Vencedores da Semifinal do Porto (Departamento de Química, Universidade do Porto)

Medalhas de Ouro

Colégio Internato dos Carvalhos

Bruno Tiago Lopes Carneiro Devesa
Ana Catarina R. dos Santos e Silva

David Armando de Oliveira Pinto

Professor: Joaquim Batista da Silva

Medalhas de Prata

ES/B3 Rio Tinto

Sérgio Marcos

Paulo Xavier

Margarida Moura

Professor: Maria José Borges

Medalhas de Bronze

ES/B3 Emídio Garcia - Bragança

Jorge Pedro Martins Nogueiro

Salomão Assis Campo Fernandes

João Pedro Esteves Bragada

Professor: Ana Cristina Ferreira

Vencedores da Semifinal de Lisboa (Instituto Superior Técnico, Universidade Técnica de Lisboa)

Medalhas de Ouro

ES José Saramago - Mafra

Alexandra Castelo

Bianca Rosca

Gonçalo Bonifácio

Professor: Maria Manuela Raposo Martins

Medalhas de Prata

ES Pinheiro e Rosa - Faro

Joana Isabel Afonso

Ana Catarina

Rafael Vieira

Professor: Ana Paula Machado

Medalhas de Bronze

ES Bocage - Setúbal

Carla Viegas

Delfim Costa

Marta Fidalgo

Professor: Maria da Conceição Brito 